\title{
Cysteine-Catalyzed Peptide Synthesis in Neutral Water
}

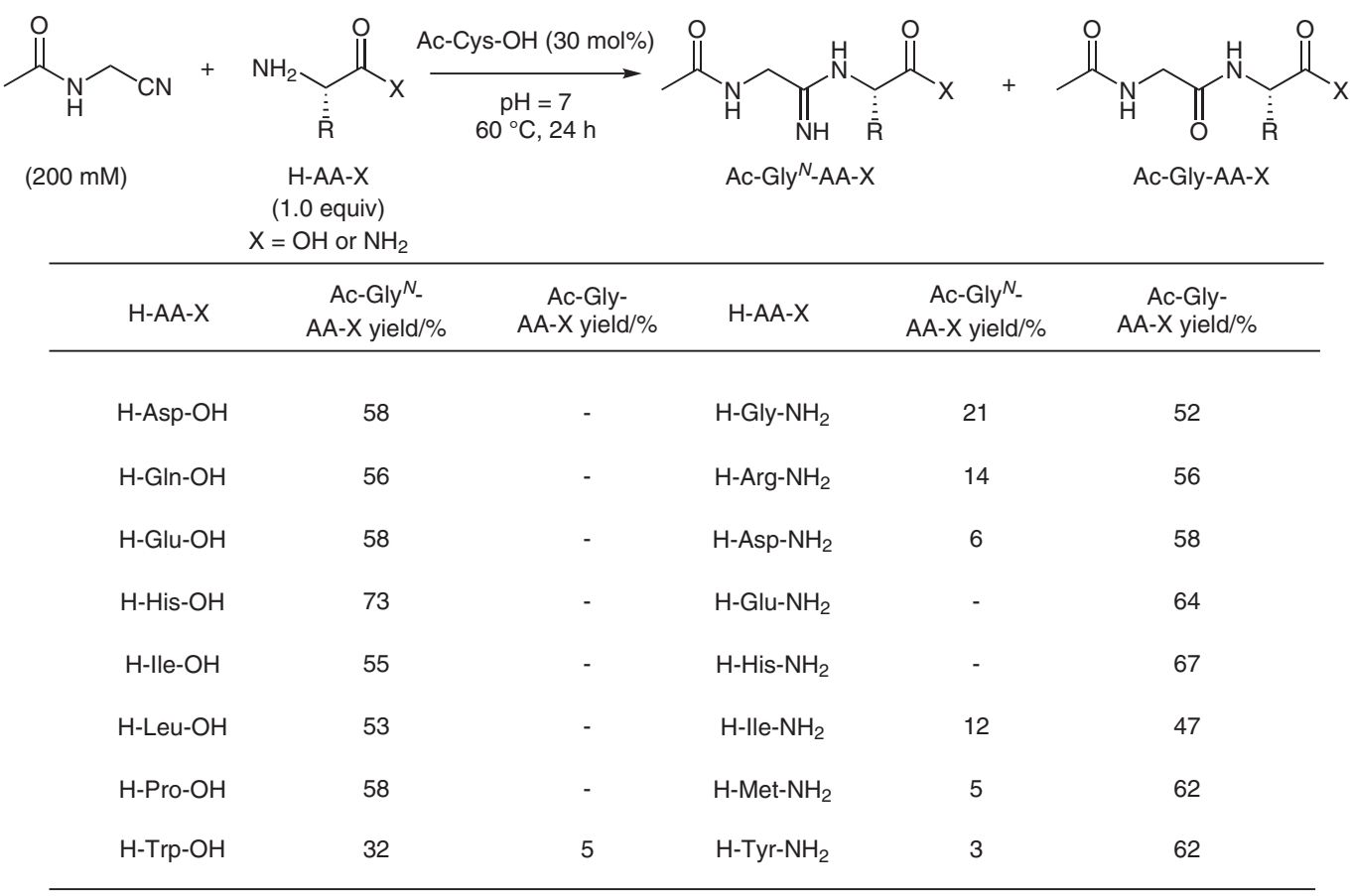

\section{Key words}

cysteine peptides

catalytic peptide ligation

aqueous media

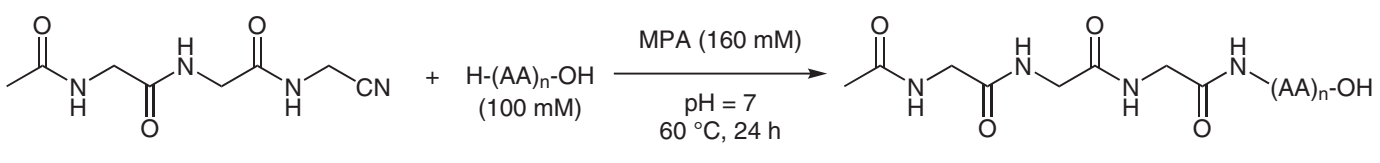

(100 mM)

MPA = 3-mercaptopropionic acid

Ac-Gly-Gly-Gly-(AA) $)_{n}-\mathrm{OH}$

$$
\begin{aligned}
& \text { Ac-Gly-Gly-Gly-Met-Gly-OH } \\
& 80 \% \text { yield } \\
& \text { Ac-Gly-Gly-Gly-Gly-Gly-Gly-OH } \\
& 89 \% \text { yield }
\end{aligned}
$$

Ac-Gly-Gly-Gly-Ala-Ala-Ala-OH $90 \%$ yield

Ac-Gly-Gly-Gly-Gly-Gly-His-OH $89 \%$ yield
Ac-Gly-Gly-Gly-Ala-Gly-Ala-OH $84 \%$ yield

Ac-Gly-Gly-Gly-Met-Ala-Ser-OH $77 \%$ yield
Significance: Cysteine is very attractive due to its high reactivity as a nucleophile. The authors found that acylated cysteine can be synthesized in a prebiotic approach and used as a catalyst in the catalytic peptide ligation pathway to prepare oligopeptides.
Comment: With the cysteine as a catalyst, various dipeptides can be synthesized in neutral water.

When 3-mercaptopropionic acid was used instead of cysteine, oligopeptides could also be prepared in a similar thiol-catalyzed peptide-ligation manner. The yields of the target peptides are moderate to good. 